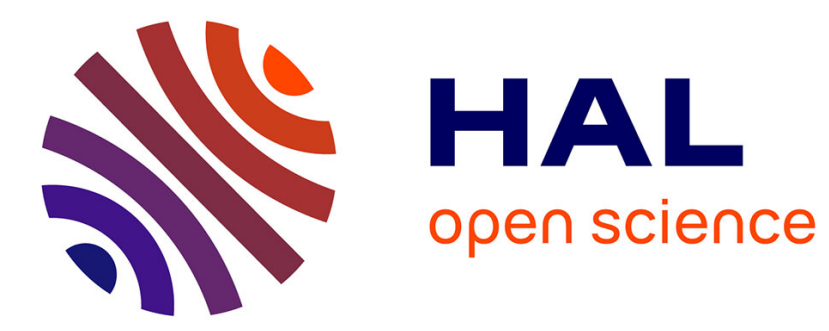

\title{
The preferred fatigue crack propagation mode in a M250 maraging steel loaded in shear \\ C. Pinna, V. Doquet
}

\section{To cite this version:}

C. Pinna, V. Doquet. The preferred fatigue crack propagation mode in a M250 maraging steel loaded in shear. Fatigue and Fracture of Engineering Materials and Structures, 1999, 22 (3), pp.173-183. 10.1046/j.1460-2695.1999.00161.x . hal-00111621

\section{HAL Id: hal-00111621 \\ https://hal.science/hal-00111621}

Submitted on 19 Oct 2020

HAL is a multi-disciplinary open access archive for the deposit and dissemination of scientific research documents, whether they are published or not. The documents may come from teaching and research institutions in France or abroad, or from public or private research centers.
L'archive ouverte pluridisciplinaire HAL, est destinée au dépôt et à la diffusion de documents scientifiques de niveau recherche, publiés ou non, émanant des établissements d'enseignement et de recherche français ou étrangers, des laboratoires publics ou privés. 


\title{
The preferred fatigue crack propagation mode in a M250 maraging steel loaded in shear
}

\author{
C. PINNA ${ }^{1}$ and V. DOQUET \\ Laboratoire de Mécanique des Solides U.M.R. CNRS, Ecole Polytechnique 91128 Palaiseau cedex, France, ${ }^{1}$ Present address: \\ Sheffield University, Mechanical Engineering Department, Mappin Street, Sheffield S1 3JD, UK
}

\begin{abstract}
Macroscopic torsional fatigue cracks are shown to propagate in shear, in plain tubular specimens, in the M250 maraging steel, for stress ranges from $90 \%$ down to $40 \%$ of the yield stress. This cannot be explained in terms of microcrack coalescence for the smallest stress range, for which microcracks are scarce. The kinetics and mechanisms of mode II fatigue crack growth are thus investigated, using precracked CTS or tubular specimens. For a high $\Delta K_{\mathrm{II}}$, slowly decelerating mode II propagation takes place for a distance that increases with $\Delta K_{\mathrm{II}}$ before branching occurs. Friction stresses along the crack flanks shield the applied load and explain this deceleration. An inverse analytical procedure is used to derive the effective stress intensity factor, allowance being made for friction effects, from displacement profiles measured from microgrids using a scanning electron microscope. The measured crack growth rates correlate much better with the effective stress intensity factor than with the nominal $\Delta K_{\mathrm{II}}$ value. The crack paths observed in torsion are discussed in terms of maximum crack velocity.
\end{abstract}

Keywords torsional fatigue, crack, mode II, propagation, friction.

\section{NOMENCLATURE}

$a=$ crack length

$a_{\mathrm{p}}=$ length of precrack

$c_{0}=$ uniform friction stress along the crack flanks

$r_{\mathrm{p}}^{\mathrm{a}}=$ length of the monotonic plastic zone ahead of the crack tip

$r_{\mathrm{p}}^{\mathrm{b}}=$ length of the monotonic plastic zone behind the crack tip

$T=$ non-singular term of the stress field parallel to a crack

$\left[u_{\mathrm{II}}\right]=$ crack flanks relative sliding displacement

$\Delta K_{\mathrm{II}}^{\mathrm{nom}}=$ nominal amplitude of the mode II stress intensity factor

$\Delta K_{\mathrm{II}}^{\text {eff }}=$ effective amplitude of the mode II stress intensity factor

$\Delta\left[u_{\mathrm{II}}\right]=$ amplitude of crack flanks relative sliding displacement

\section{INTRODUCTION}

Although uniaxial fatigue cracks usually grow in mode I in polycrystals, shear mode propagation has been observed in a number of materials under high- and lowamplitude torsional loading. For materials, e.g. stainless steels, in which shear mode propagation is observed only in the range of low cycle fatigue, ${ }^{1}$ this might partly be due to microcracks coalescence. However, in highstrength materials, e.g. Inconel $718,{ }^{1}$ macroscopic shear cracks are also formed in high-cycle fatigue, a domain where the explanation given above does not hold. Thus, it seems that an independent mode II or III development of a fatigue crack is possible, provided the range of the stress intensity factor lies above a given threshold. A similar conclusion was derived by Otsuka et al. for a 7075-T6 aluminium alloy from threshold measurements in mixed mode on precracked specimens: ${ }^{2}$ for low $\Delta K_{\mathrm{II}}$ values, branching occurred, whereas for higher values, mode II growth prevailed. On the other hand, a number of studies devoted to the determination of propagation thresholds in mixed mode (see, e.g. Ref. 3) have shown that some mode II propagation from a precrack tip was possible, although terminating in crack arrest, for $\Delta K_{\mathrm{II}}$ 
values below a threshold, above which branching occurred.

Mode II as well as mode III crack growth kinetics have been shown to depend largely on crack flanks frictional interactions ${ }^{4,5}$ responsible for crack deceleration, branching or arrest, at constant nominal $\Delta K_{\mathrm{II}}$ or $\Delta K_{\mathrm{III}}$. The pertinent parameters for the delimitation of the domain(s?) in which shear or opening mode propagation are preferred are obviously not these nominal values but rather the effective values.

The present study takes advantage of the plane geometry associated with mode II propagation, that allows direct observation of a crack tip and its flanks, to measure the effective $\Delta K_{\mathrm{II}}$ and find an intrinsic relation with the crack growth rate for a M250 maraging steel. The crack propagation trajectories observed in torsional fatigue in this material are then analysed in terms of maximum velocity. The apparent contradiction in the literature concerning the conditions for which mode II can be observed is then discussed.

\section{EXPERIMENTAL PROCEDURE}

The material investigated is a M250 maraging steel $\left(\mathrm{Z} 2 \mathrm{NKD} 18-8-5, R_{0.2}=1910 \mathrm{MPa}, R_{\mathrm{u}}=1973 \mathrm{MPa}\right)$. It is used for aeroplane turboreactors shafts that support both tensile/compressive and torsional loads in service. Its chemical composition is (in wt\%): $\mathrm{Ni} 18.29$, Co 8.13, Mo 4.76, Ti 0.45, Al 0.1, C 0.008, Ca $<0.05$, B $<0.0024$.

Three types of specimens are used in this study: plain tubular specimens; tubular specimens with a circular hole of $1 \mathrm{~mm}$ in diameter in the middle of the gauge length [Fig. 1(a)]; and compact-tension-shear (CTS) specimens [Fig. 1(b)].

Stress-controlled reversed torsion tests were performed on plain tubular specimens in order to characterize the failure mode at various stress ranges.

Smith and Smith ${ }^{5}$ stressed the influence of precracking techniques on further mode II propagation. According to their recommendations, the precracking of CTS and pierced tubular specimens was conducted at an $R$ ratio of 0.3 , under constant and low $\Delta K_{\mathrm{I}}(15 \mathrm{MPa} \sqrt{\mathrm{m}})$, though not too close to the mode I threshold, as a compromise between two requirements: i.e. low residual stresses at the crack tip and limited roughness of the precrack.

Approximately $1 \mathrm{~mm}$-long precracks were thus produced on each side of the hole in tubular specimens as well as from the notch tip in CTS specimens.

Square-shaped metallic microgrids, with a $5 \mu \mathrm{m}$ pitch, produced by microelectrolithography, were then laid on the specimens ahead of the crack tip and along the crack flanks.

Mode II crack propagation tests were then carried out at $0.5 \mathrm{~Hz}$ with $K_{\min } / K_{\max }$ equal to zero for the CTS (a)

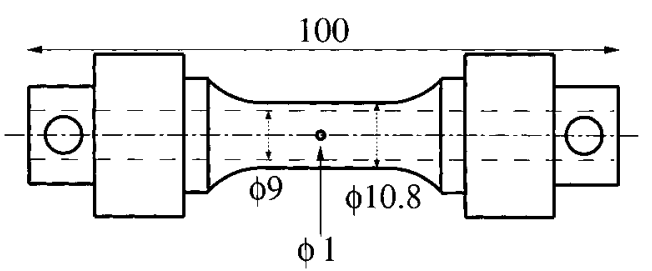

(b)

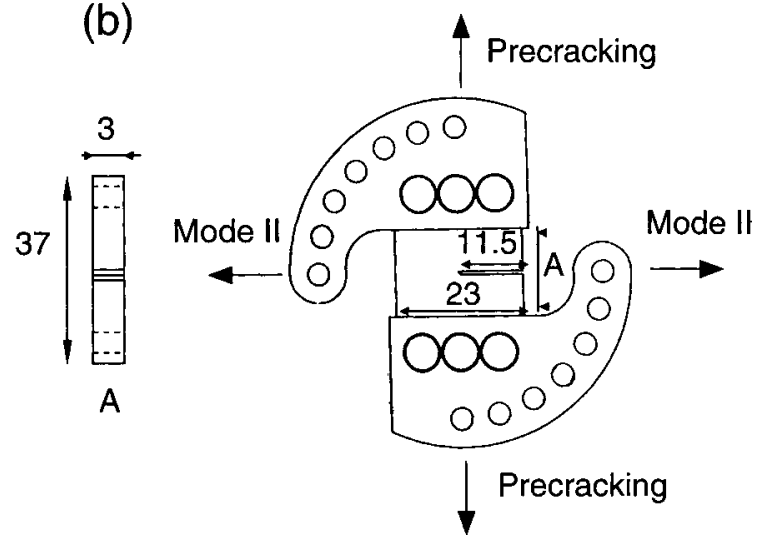

Fig. 1 Specimens geometry. (a) Pierced tubular specimen (plain tubular specimens are similar, except for the hole in the gauge length). (b) CTS specimen (dimensions in $\mathrm{mm}$ ).

specimens (tested on a conventional push-pull machine), and $R=-1$ for tubular specimens, tested in reversed torsion on a biaxial testing machine. During some of the tests performed on pierced tubular specimens, a static compressive stress of $150 \mathrm{MPa}$ was superimposed on the cyclic shear stress in order to enhance crack flank friction.

For CTS specimens, the expression for $K_{\text {II }}$ obtained by Smith and Smith ${ }^{5}$ through finite element calculations was used, whereas for tubes, the expression of $K_{\text {II }}$ given by Murakami ${ }^{6}$ was used for a circumferential throughcrack in a cylindrical shell subjected to torsion which incorporates a correction for curvature.

The size of the monotonic plastic zone was estimated by applying the von Mises criterion to the plane stress crack tip stress field. ${ }^{7}$ Ahead of the crack tip:

$r_{\mathrm{p}}^{\mathrm{a}}=\frac{3}{2 \pi}\left(\frac{K_{\mathrm{II}, \mathrm{max}}^{\mathrm{eff}}}{\sigma_{\mathrm{y}}}\right)^{2}$

and behind the crack tip:

$\pi_{\mathrm{p}}^{\mathrm{b}}=\frac{4}{2 \pi}\left(\frac{K_{\mathrm{II}, \mathrm{max}}^{\mathrm{eff}}}{\sigma_{\mathrm{y}}}\right)^{2}$

were such that small-scale yielding conditions prevailed for all our tests (see below for the definition of $K_{\text {II }}^{\text {eff }}$ ).

Cyclic mode II tests were periodically interrupted, and CTS or pierced tubular specimens transferred to a special tension and torsion loading frame that was able to work inside the chamber of a scanning electron 
microscope. ${ }^{8}$ The relative displacements of the crack flanks were then measured at both $K_{\min }$ and $K_{\max }$, using microgrids as reference marks, and the crack propagation mechanisms as well as the interactions between the crack and microstructure could be observed.

A single test on a CTS specimen was performed entirely in situ at a very low frequency $(0.025 \mathrm{~Hz})$, partly in air and partly in the secondary vacuum of the SEM chamber.

\section{RESULTS}

\section{Reversed torsion tests on plain tubular specimens}

The fatigue lives measured in reversed torsion on plain tubular specimens are given in Table 1. The main crack trajectories as well as SEM pictures of the network of microcracks in representative areas of the same specimen surfaces, at fracture, are shown in Figs 2 and 3. For the three highest stress ranges, a transverse crack more than $14 \mathrm{~mm}$ long has developed in shear mode until a structural instability produced branches that were observable

specimen axis
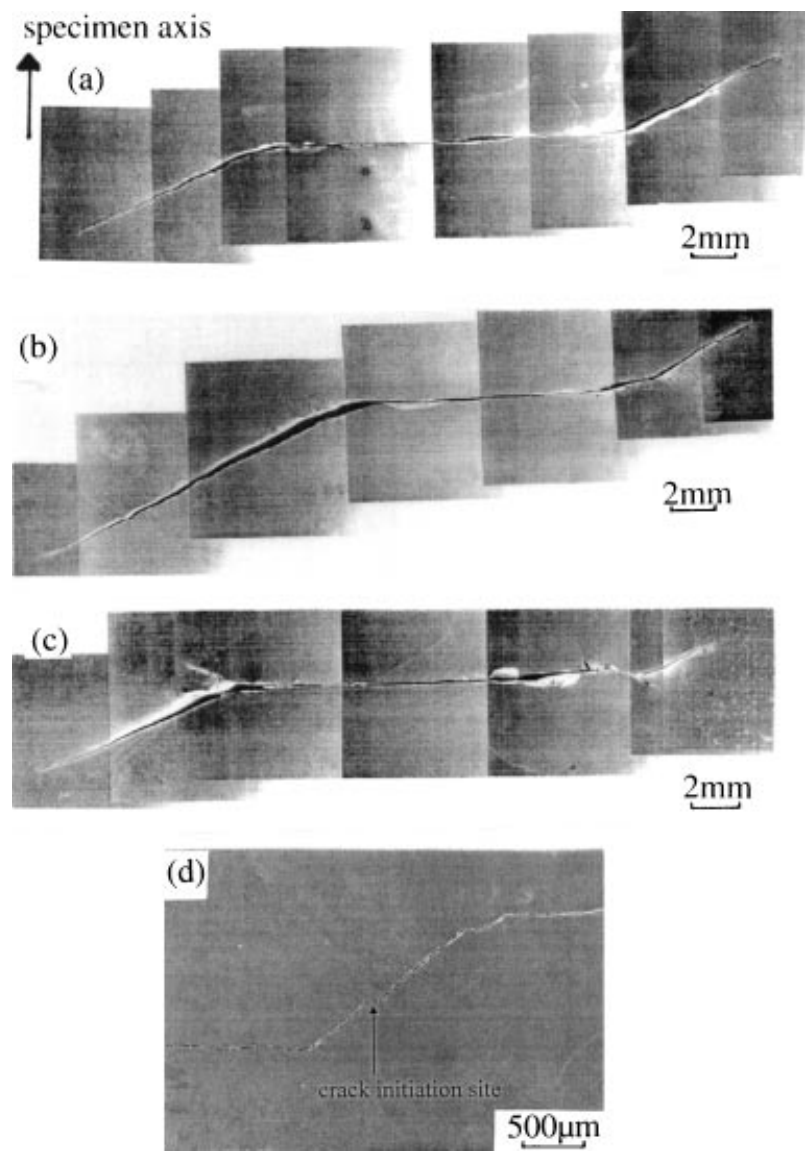

Fig. 2 Main crack trajectories in reversed torsion, in plain tubular specimens. (a) $\Delta \tau / 2=900 \mathrm{MPa}$, (b) $\Delta \tau / 2=700 \mathrm{MPa}$, (c) $\Delta \tau / 2=$ $550 \mathrm{MPa}$, (d) $\Delta \tau / 2=400 \mathrm{MPa}$.
Table 1 Results of reversed torsion tests on plain tubular specimens

\begin{tabular}{llllll}
\hline$\Delta \tau / 2(\mathrm{MPa})$ & 900 & 700 & 550 & 400 & 395 \\
\hline$N_{\mathrm{f}}$ (cycles) & 500 & 3000 & 14000 & 116000 & 199000 \\
\hline
\end{tabular}
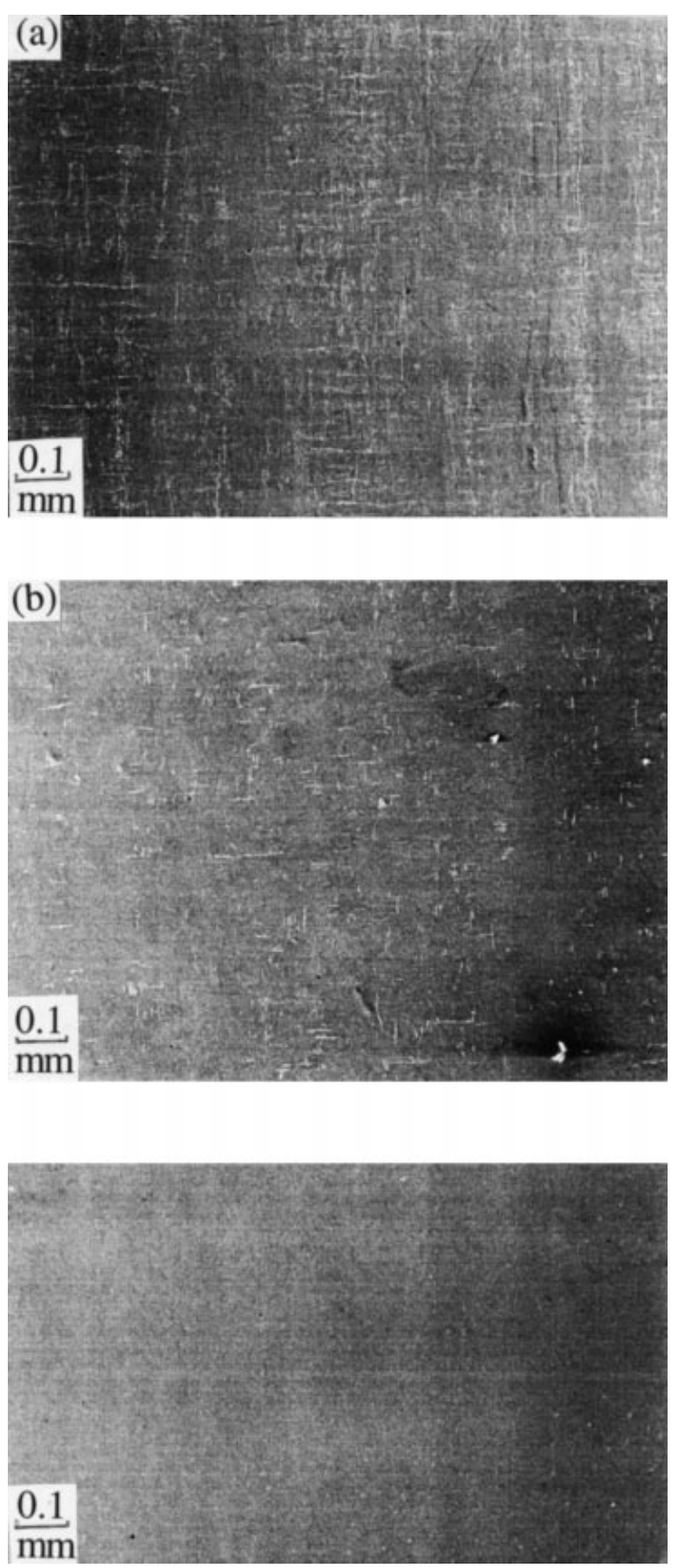

Fig. 3 Fatigue damage in reversed torsion, in plain tubular specimens, at failure. (a) $\Delta \tau / 2=900 \mathrm{MPa}$, (b) $\Delta \tau / 2=700 \mathrm{MPa}$, (c) $\Delta \tau / 2=550 \mathrm{MPa}$. 
at each end of the crack. For the highest stress range (approximately $\pm 90 \%$ of the shear yield stress), the network of cracks is very dense and equally distributed on the two maximum shear strain planes (longitudinal and transversal). Coalescence phenomena have probably contributed to the formation of the main transverse crack. For the intermediate stress range $( \pm 70 \%$ of the yield stress), microcracks are less numerous, especially in the longitudinal direction, whereas for the lowest amplitude ( $\pm 55 \%$ of the yield stress), hardly any microcracks could be observed. In the latter case, it is clear that the formation of a macroscopic shear crack cannot be explained by coalescence phenomena.

For a smaller amplitude $( \pm 400 \mathrm{MPa})$, the crack initiated along a transverse plane, and after developing over $75 \mu \mathrm{m}$ in stage I, branched to grow in the opening mode as usually observed in stage II [see Fig. 2(d)]. However, after a mode I growth over $1.6 \mathrm{~mm}$, the crack branched again to propagate transversally anew for more than $10 \mathrm{~mm}$ [the crack profile is truncated in Fig. 2(d)]. A similar test was performed again, with periodic interruptions, and observations of the specimen noted, in order to see if this rather unusual behaviour would occur again. Once again, the main crack was observed to grow first at $45^{\circ}$ to the axis, at an increasing rate, and to branch to a transverse direction when its length was $3 \mathrm{~mm}$ and its growth rate reached $\approx 0.1 \mu \mathrm{m} /$ cycle. The accelerating shear mode propagation finally led to failure.

\section{Mode II crack propagation tests}

\section{Crack propagation mechanisms}

The tests carried out on CTS specimens under constant $\Delta K_{\mathrm{II}}$ values ranging from 18 to $30 \mathrm{MPa} \sqrt{\mathrm{m}}$ gave rise to some mode II crack development up to a certain length, after which branching occurred (Fig. 4).

Under the SEM, some local opening displacements induced by the asperities of the crack flanks can be observed, essentially in the precracked part, that shows a $\pm 45^{\circ}$ zig-zag profile [Fig. 5(a)], but most of the crack, and above all the crack tip, remained closed.

The profile of the cracks which developed in mode II is generally very flat [Fig. 5(b)]. The cracks follow the coplanar slip bands formed at the crack tip, except in the presence of strong microstructural obstacles (the precise nature of which could not be determined). The activation of a second slip system (on which the shear stress, evaluated from the elastic stress field at the crack tip, is less than on the coplanar system) permits the bypassing of these obstacles and generates occasional 'steps', 5-15 $\mu \mathrm{m}$ high, along the crack flanks. These steps provide the main resistance force to the sliding displacement of the crack flanks under load (Fig. 6), but tend to be worn out progressively by sliding friction. A large

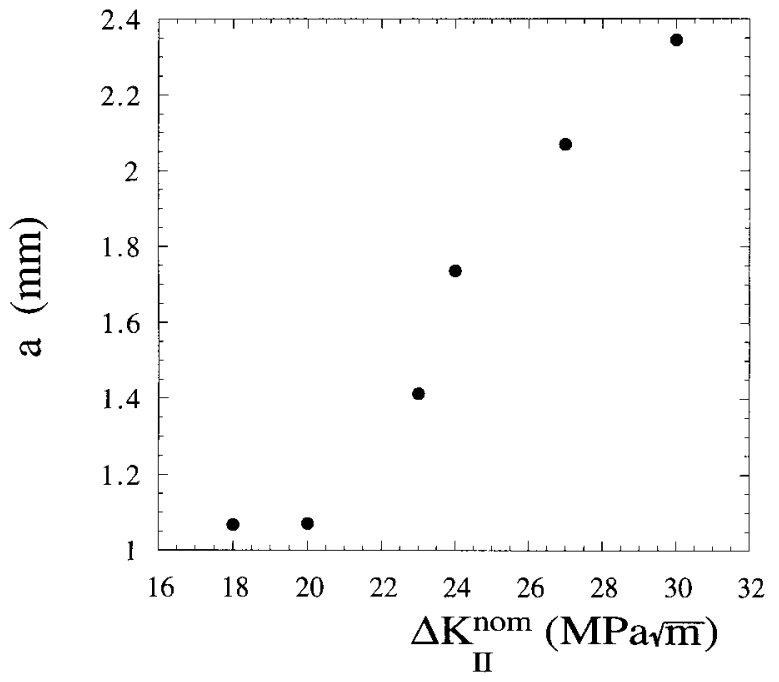

Fig. 4 Lengths of cracks at the onset of branch development in CTS specimens.

quantity of fretting debris continuously comes out of the crack flanks and has to be removed to allow observation. Wear is also evident from the smeared-out fracture surfaces on which $1 \mu \mathrm{m}$ 'furrows' parallel to the crack propagation direction can be observed [Fig. 7(a)]. Such furrows were also observed on the fracture surfaces of the plain tubular specimen tested in torsion at $\pm 900 \mathrm{MPa}$, much better preserved from wear thanks to a faster crack propagation (due to stress control, instead of constant $\Delta K$ ) [Fig. 7(b)]. They could have been formed by the ploughing action of hard particles embedded in one of the crack flanks and thus moving to and fro. However, the length of these furrows $(50-100 \mu \mathrm{m})$ is generally much higher than the amplitude of the relative sliding displacement (at most $20 \mu \mathrm{m}$, close to the notch root), so that an important dragging of the particles after they are detached has to be assumed.

\section{Mode II crack growth kinetics}

The kinetics of mode II crack growth under constant $\Delta K_{\text {II }}$ determined on CTS specimens are reported in Fig. 8(a), in which the precrack length for each specimen is indicated in brackets. It can be seen that the crack propagation rates do not scale with the applied nominal $\Delta K_{\mathrm{II}}$ but are very dependent on the precrack length, $a_{\mathrm{p}}$. The crack growth rate for $\Delta K_{\mathrm{II}}=20 \mathrm{MPa} \sqrt{\mathrm{m}}$ and $a_{\mathrm{p}}=$ $910 \mu \mathrm{m}$ is higher than for $\Delta K_{\mathrm{II}}=23 \mathrm{MPa} \sqrt{\mathrm{m}}$ and $a_{\mathrm{p}}=$ $1078 \mu \mathrm{m}$. The same is true for $\Delta K_{\mathrm{II}}=24 \mathrm{MPa} \sqrt{\mathrm{m}}$, $a_{\mathrm{p}}=936 \mu \mathrm{m}$, compared to $\Delta K_{\mathrm{II}}=27 \mathrm{MPa} \sqrt{\mathrm{m}}, a_{\mathrm{p}}=$ $1109 \mu \mathrm{m}$. This is because the nominal $\Delta K_{\text {II }}$ does not integrate the various friction forces that result from various precrack lengths and roughness.

If the crack growth rates are very sensitive to the 
Fig. 5 Typical aspects of a crack loaded in shear, as seen in the SEM. (a) Precracked part. (b) Mode II part. (Pitch of the grid: $5 \mu \mathrm{m}$.)
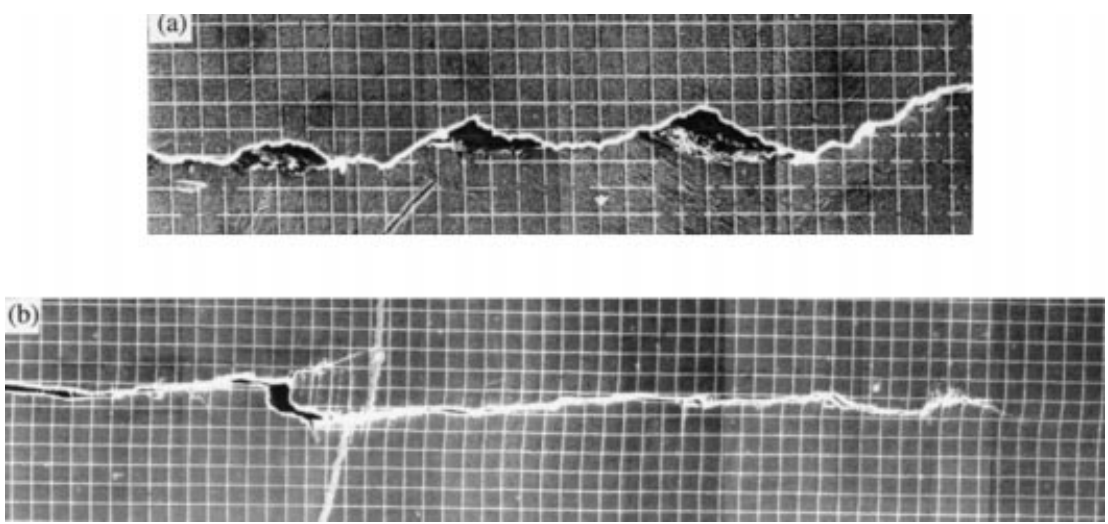
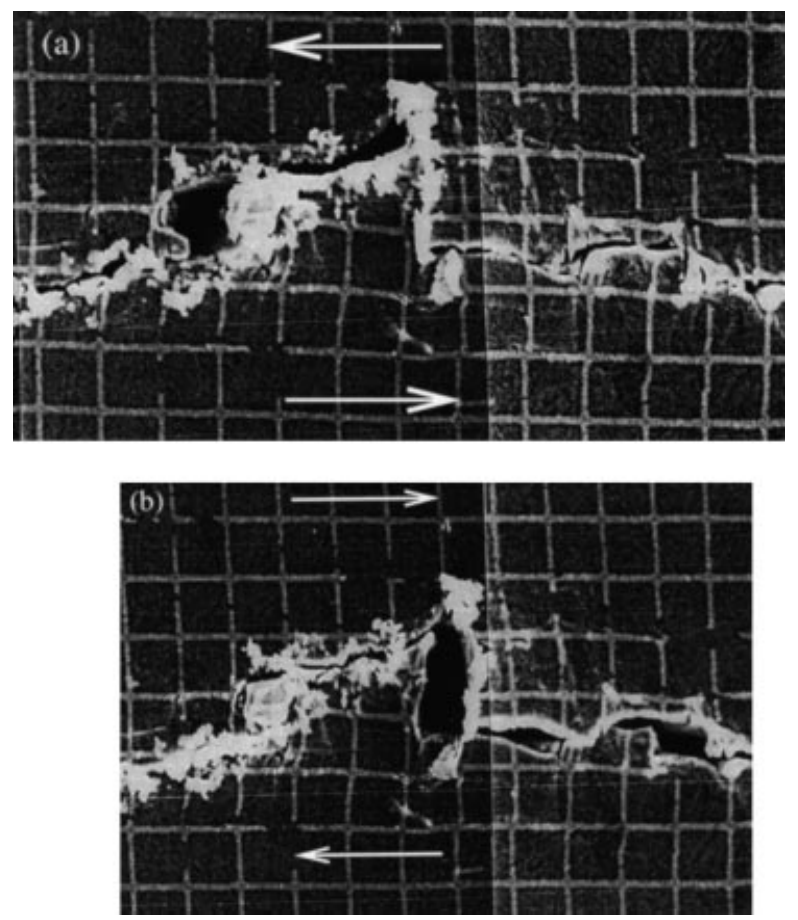

Fig. 6 Contact of crack flanks at asperities under shear loading. (Pitch of the grid: $5 \mu \mathrm{m}$.)

precrack length, they do not, however, vary very quickly with the length of the mode II crack; there is almost no discernable slowing down before branching. This is because the smooth mode II cracks, except for the occasional 'steps' formed along their flanks, do not contribute as much to friction forces as the rough precracks. A deceleration was, however, discernable at higher $\Delta K_{\mathrm{II}}(37 \mathrm{MPa} \sqrt{\mathrm{m}})$, when a crack kept growing in the coplanar direction for more than $5 \mathrm{~mm}$ without branching [Fig. 8(b)].

Environment effects were observed during the test entirely performed on the in situ loading frame for $\Delta K_{\mathrm{II}}=27 \mathrm{MPa} \sqrt{\mathrm{m}}$. First, the crack growth rate under vacuum was only half of the rate in air, which may be partly explained by an increase in the friction coefficient
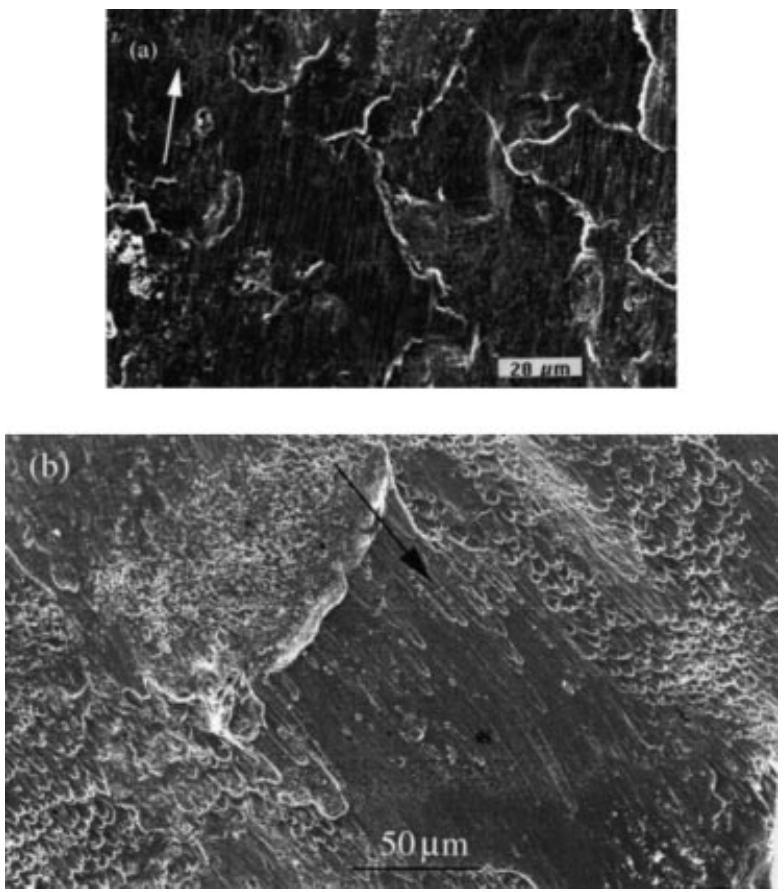

Fig. 7 Typical aspects of fracture surfaces. (a) 'Furrows' on the fracture surface of a CTS specimen. (b) Elongated voids on the fracture surface of a plain tubular specimen. The direction of propagation is indicated by arrows.

under vacuum (see Ref. 9). Second, the crack growth rate in air at the low loading frequency used $(0.025 \mathrm{~Hz})$ was approximately twice as high as for $0.5 \mathrm{~Hz}$ for the same nominal $\Delta K_{\mathrm{II}}$, and this made mode II growth more stable; instead of branching at a final length of $950 \mu \mathrm{m}$, as expected from Fig. 4, the crack kept growing in mode II (though slowly decelerating) for more than $3 \mathrm{~mm}$. Frequency effects associated with hydrogen embritlement have been reported for mode I propagation in a maraging steel ${ }^{10}$ and may perhaps affect mode II propagation as well. Further investigations on that point are in progress. 

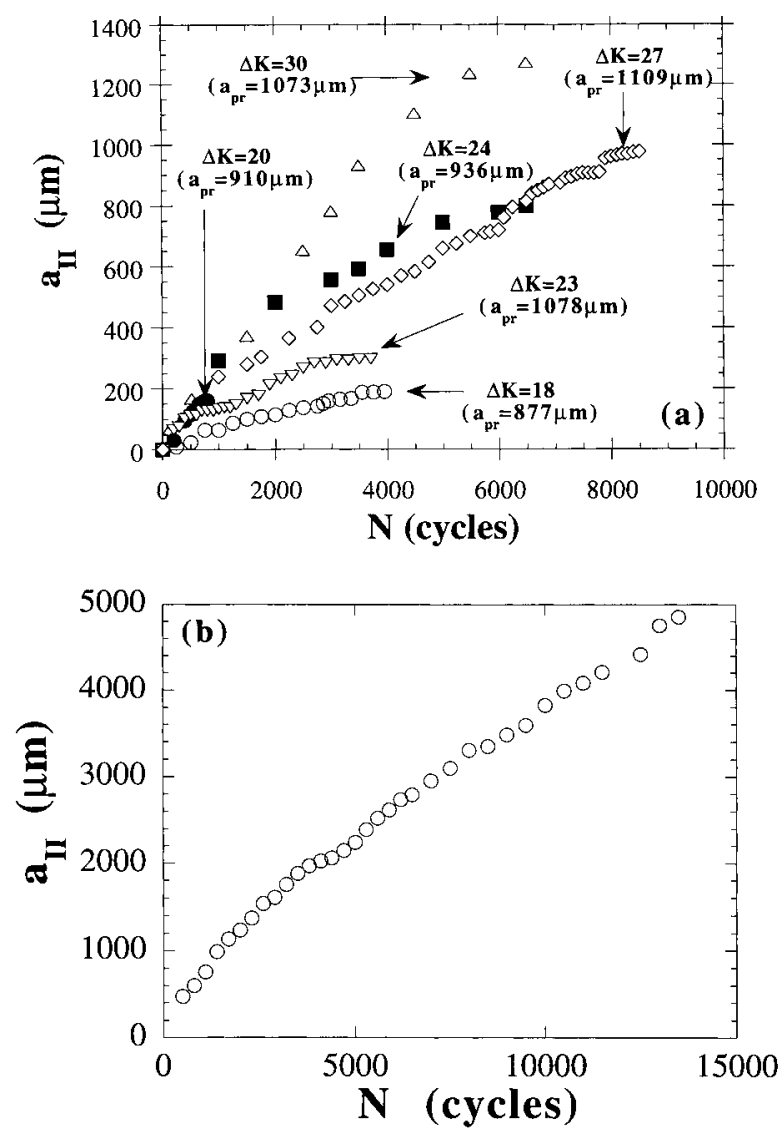

Fig. 8 Kinetics of mode II crack propagation as measured in CTS specimens for a constant nominal $\Delta K_{\mathrm{II}}$. (a) For values of $\Delta K_{\mathrm{II}}$ between 18 and $30 \mathrm{MPa} \sqrt{\mathrm{m}}$. (b) For $\Delta K_{\mathrm{II}}=37 \mathrm{MPa} \sqrt{\mathrm{m}}$.

\section{Crack flank displacements}

Two of the profiles of relative sliding displacements, measured on CTS or precracked tubular specimens, along the crack flanks are shown in Fig. 9, together with the theoretical profiles associated with a nominal $\Delta K_{\mathrm{II}}$, i.e. for plane stress: ${ }^{7}$

$$
\begin{gathered}
\Delta\left[u_{\mathrm{II}}\right]=\frac{8 \Delta K_{\mathrm{II}} / r}{E \sqrt{2 \pi}} \quad \text { where }\left[u_{\mathrm{II}}\right]=u(\pi)-u(-\pi) \\
\text { and } \Delta\left[u_{\mathrm{II}}\right]=\left[u_{\mathrm{II}}\right]^{\max }-\left[u_{\mathrm{II}}\right]^{\min }
\end{gathered}
$$

Even though the measured displacement varies as $\sqrt{r}$ beyond the plastic zone (Fig. 10), the measured amplitudes of mode II displacements are less than the amplitudes evaluated with the nominal $\Delta K_{\mathrm{II}}$, and the attenuation, due to friction force is especially important when a compressive stress enhances interactions of the crack flanks [Fig. 9(b)].

The stress field at the crack tip, related to the displacement field through the constitutive equations, is thus also shielded by friction. The effective crack driving force $\Delta K_{\mathrm{II}}^{\mathrm{eff}}$, which is less than the nominal $\Delta K_{\mathrm{II}}$, has to
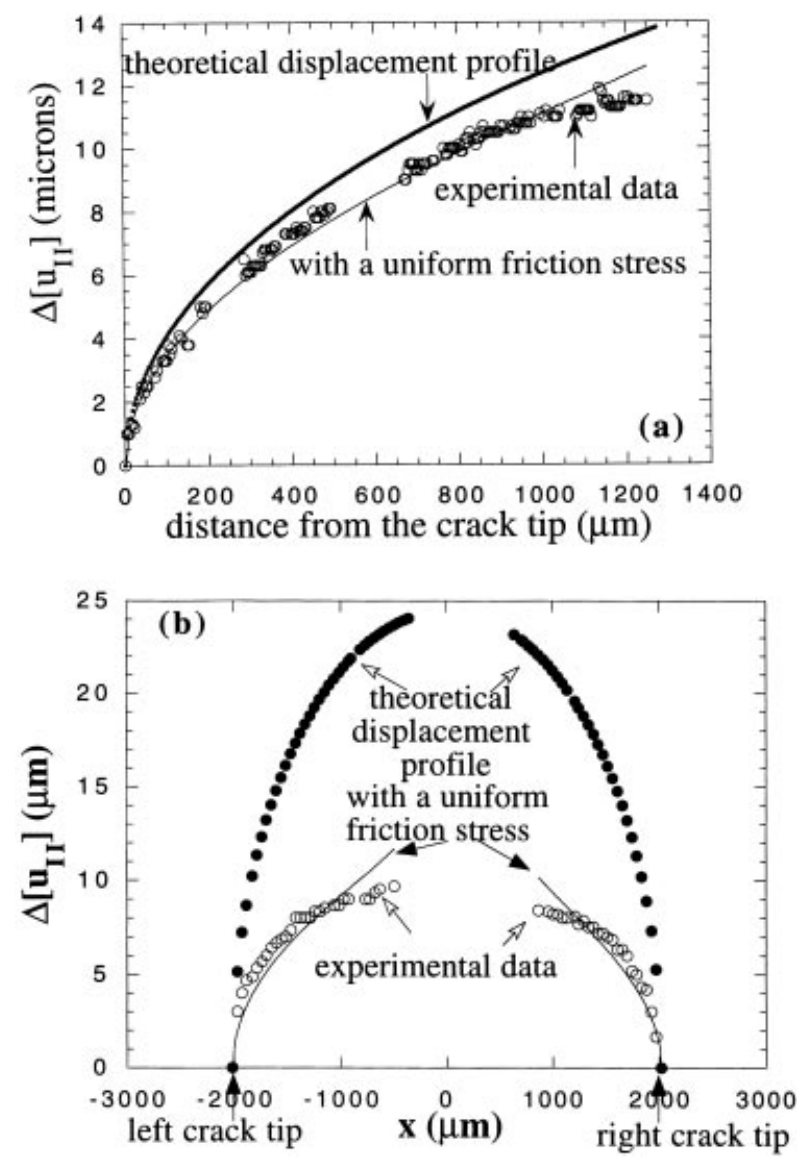

Fig. 9 Amplitude of relative tangential displacements along the crack flanks. (a) In a CTS specimen, and (b) in a tubular specimen, with a superimposed static compression stress of $150 \mathrm{MPa}$.

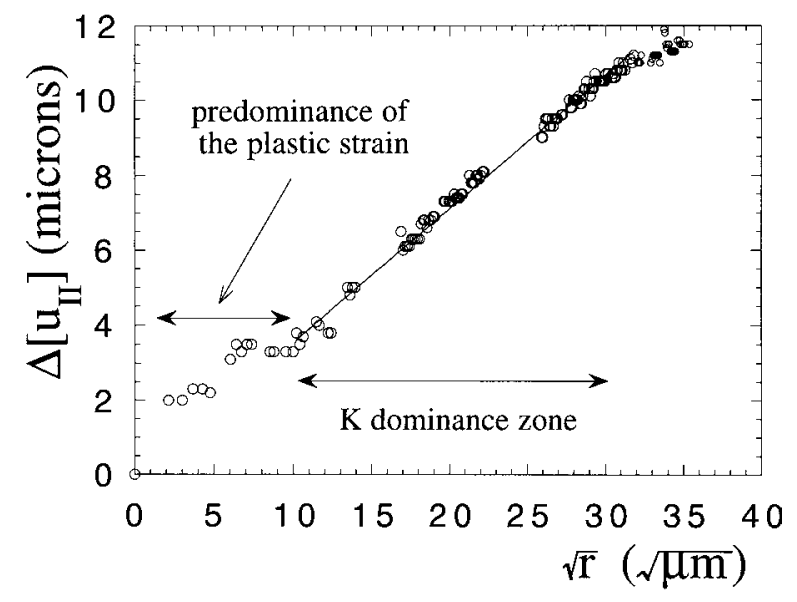

Fig. 10 Displacement profile versus the square root of the distance to the crack tip.

be determined. Note that it would be wrong to fit the experimental displacement profile with Eq. (1) in which $\Delta K_{\mathrm{II}}^{\mathrm{eff}}$ would replace $\Delta K_{\mathrm{II}}^{\mathrm{nom}}$, because friction forces exist 
only along the precrack and the mode II crack flanks, and not along the notch.

\section{Plot of the crack growth rates versus $\Delta \mathrm{K}_{I I}^{\text {nom }}$}

The crack growth rates measured on precracked tubular specimens or CTS specimens, for $R=-1$ and 0 , respectively, are shown in Fig. 11(a) versus nominal $\Delta K_{\mathrm{II}}$. A clear lack of correlation appears, especially when the data obtained with a static compressive stress are compared to those of pure mode II, because the enhancement of friction is not taken into account by the nominal $\Delta K_{\mathrm{II}}$. Besides, contrary to mode I propagation, there seems to be no effect of the $R$ ratio on the mode II crack
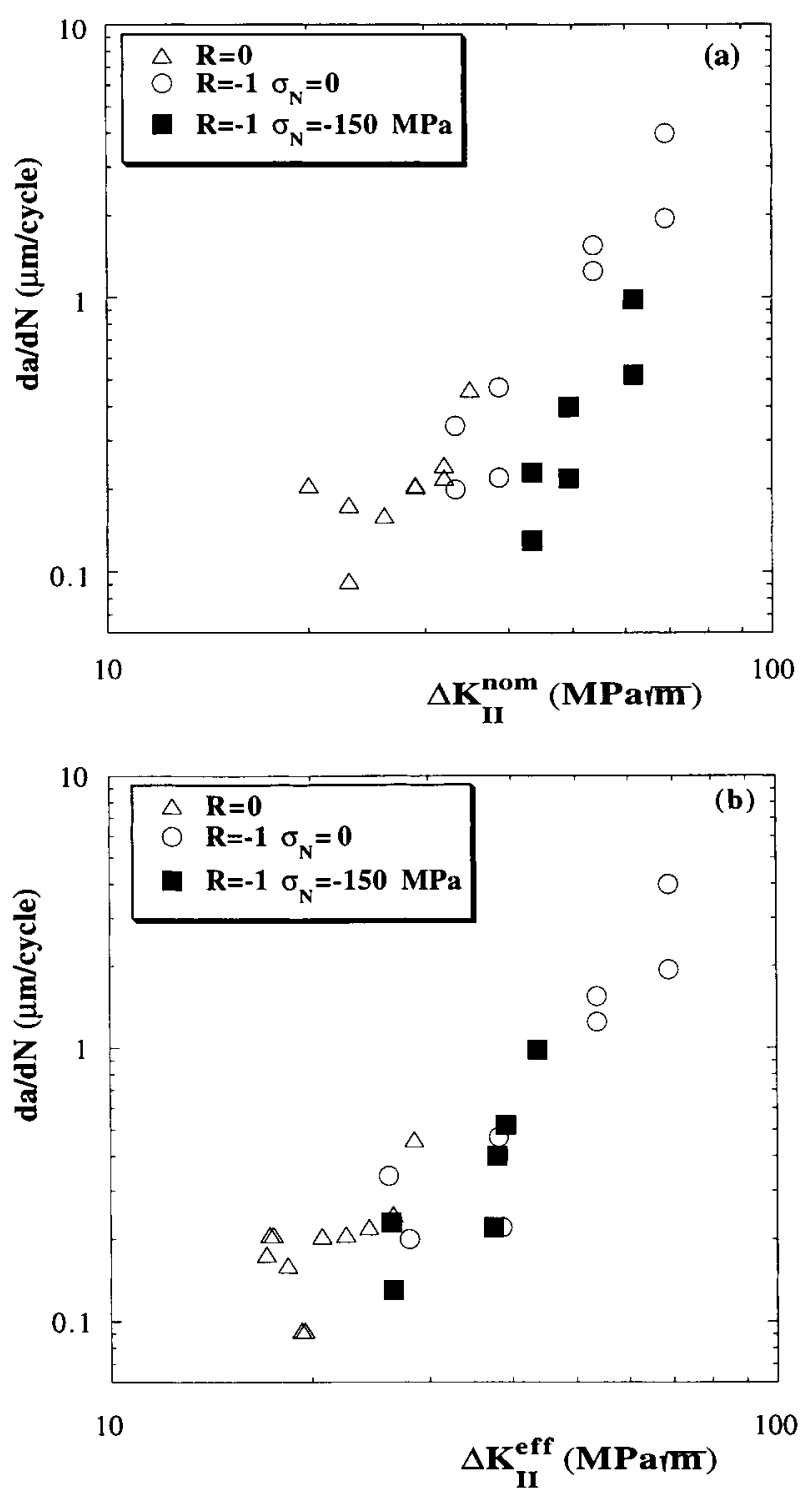

Fig. 11 Crack growth rates versus (a) nominal and (b) effective stress intensity factors. growth rate. This is in line with the conclusions of Otsuka et al. ${ }^{2}$ who also studied long mode II cracks. By contrast, Wang and Miller ${ }^{11}$ observed an acceleration of stage I-mode II + III crack growth in $1.99 \% \mathrm{NiCrMo}$ steel, in the presence of a mean shear stress, in torsional fatigue. The reason for this detrimental effect, observed mainly on short cracks, might be because a mean shear stress could assist the microcracks in their crossing of grain boundaries, especially difficult in torsion, ${ }^{12,13}$ by enhancing the stress concentration ahead of the slip band emanating from the crack tip and blocked by the grain boundary.

\section{Determination of the effective range of the stress intensity factor}

A semianalytical inverse method has been developed to deduce $\Delta K_{I I}^{\text {eff }}$ from the measured displacement profiles. This was described in detail in Ref. 14, and only useful results will be recalled here. The calculations consider cracks of length $2 a$ in infinite plates loaded by a shear force $Q^{\prime}$ chosen so as to ensure the equality of the nominal stress intensity factors in the real and idealized geometries.

Analytical expressions of the displacement profiles along the crack flanks due to the superposition of $Q^{\prime}$, and of a uniform friction stress $c_{0}$ present over a portion $a-a_{0}$ of the crack in the case of CTS specimens, $a-a_{0}$ and $a-a_{1}$ on each side of the hole in tubular specimens were obtained. The friction stress $c_{0}$ is then adjusted so as to best fit the experimental displacement profiles considering only the points in the $K$ dominance zone of Fig. 10. The points that are too close to the crack tip and for which plastic strain predominates, as well as those situated too far away for which higher order terms become important, are thus not taken into account. The assumption of a uniform friction stress leads to a satisfying description of measured displacements, as illustrated in Fig. 9.

The value of $c_{0}$ determined by this procedure is then put into the expression of $\Delta K_{\mathrm{II}}^{\mathrm{eff}}$; i.e. for CTS specimens:

$\frac{\Delta K_{\mathrm{II}}^{\mathrm{eff}}}{\sqrt{\pi a}}=\left[Q^{\prime}-2 c_{0}\left(\frac{\sqrt{a^{2}-a_{0}^{2}}}{\pi a}+1-\frac{2}{\pi} \arctan \left(\sqrt{\frac{a+a_{0}}{a-a_{0}}}\right)\right)\right]$

and for tubular specimens, allowance is made for the different crack lengths on each side of the hole:

$$
\begin{aligned}
& \Delta K_{\mathrm{II}}^{\mathrm{eff}}=2\left\{Q^{\prime}-c_{0}\left[\frac{\sqrt{a^{2}-a_{0}^{2}}-\sqrt{a^{2}-a_{1}^{2}}}{\pi a}+1\right.\right. \\
& \left.\left.-\frac{2}{\pi}\left(\arctan \sqrt{\frac{a+a_{0}}{a-a_{0}}}-\arctan \sqrt{\frac{a-a_{1}}{a+a_{1}}}\right)\right]\right\} \sqrt{\pi a}
\end{aligned}
$$


on the right, and

$$
\begin{aligned}
& \Delta K_{\mathrm{II}}^{\mathrm{eff}}=2\left\{Q^{\prime}-c_{0}\left[\frac{\sqrt{a^{2}-a_{1}^{2}}-\sqrt{a^{2}-a_{0}^{2}}}{\pi a}+1\right.\right. \\
& \left.\left.-\frac{2}{\pi}\left(\arctan \sqrt{\frac{a+a_{1}}{a-a_{1}}}-\arctan \sqrt{\frac{a-a_{0}}{a+a_{0}}}\right)\right]\right\} \sqrt{\pi a}
\end{aligned}
$$

on the left.

The measurement precision of the displacement amplitude is $\pm 0.6 \mu \mathrm{m}$. The precision on $\Delta K_{\mathrm{II}}^{\text {eff }}$ is thus approximately $\pm 1.5 \mathrm{MPa} \sqrt{\mathrm{m}}$. The values of $\Delta K_{\mathrm{II}}^{\text {eff }}$ determined by this procedure for CTS specimens are reported in Table 2(a), for two tests carried out under constant $\Delta K_{\mathrm{II}}$, and for a test under increasing and then decreasing $\Delta K_{\mathrm{II}}$. Table 2(b) displays results concerning precracked tubular specimens loaded in pure shear or with a static compressive stress.

Values of $\Delta K_{\mathrm{II}}^{\mathrm{eff}}$ do not vary very significantly during the tests performed on CTS specimens at $20 \mathrm{MPa} \sqrt{\mathrm{m}}$ and $23 \mathrm{MPa} \sqrt{\mathrm{m}}$, which is consistent with the limited variations in the crack growth rates observed during these tests [see Fig. 8(a)]. A decrease of $\Delta K_{\text {II }}^{\text {eff }}$ down to a threshold below which mode I crack growth becomes more favourable is, however, believed to justify the final branching. Here, this decrease is not clear, because
$\Delta K_{\mathrm{II}}^{\mathrm{eff}}$ was close to the threshold for branching (estimated as $17 \mathrm{MPa} \sqrt{\mathrm{m}}$ ) from the beginning of the tests, so that its fluctuations were of the same order of magnitude as the precision on $\Delta K^{\mathrm{eff}}$. Additional measurements under conditions giving rise to a longer mode II propagation path, e.g. the low-frequency tests mentioned above, should illustrate this effect more definitely.

The values of $c_{0}$ determined on the tubular specimen for $\Delta K_{\mathrm{II}}=33.3 \mathrm{MPa} \sqrt{\mathrm{m}}$ are close to those measured on CTS specimens, but above $38.7 \mathrm{MPa} \sqrt{\mathrm{m}}$, the generalized asperity-induced opening of the crack explains the reduction of $c_{0}$ to zero. Such an opening is prevented, on specimen, by the presence of a compressive stress that is responsible for a marked increase in the friction stress, $c_{0}$. The crack growth rates are plotted versus $\Delta K_{\mathrm{II}}^{\mathrm{eff}}$ in Fig. 11(b), in which the scatter is clearly less than in Fig. 11(a).

\section{DISCUSSION}

Tests on precracked CTS or tubular specimens have shown that when $\Delta K_{\mathrm{II}}^{\text {eff }}<17 \mathrm{MPa} \sqrt{\mathrm{m}}$, mode II propagation gives way to the development of a branch crack in mode I. However, in plain tubular specimens submitted to reversed torsion, microstructurally long cracks (a)

\begin{tabular}{llrrl}
\hline $\begin{array}{l}\text { CTS } \\
\text { specimen }\end{array}$ & $\begin{array}{l}\Delta K_{\mathrm{II}}^{\text {nom }} \\
(\mathrm{MPa} \sqrt{\mathrm{m}})\end{array}$ & $a(\mu \mathrm{m})$ & $c_{0}(\mathrm{MPa})$ & $\begin{array}{l}\Delta K_{\mathrm{II}}^{\text {eff }} \\
(\mathrm{MPa} \sqrt{\mathrm{m}})\end{array}$ \\
\hline 8 & 20 & 965 & 23 & 17.5 \\
8 & 20 & 1000 & 31 & 17.3 \\
9 & 23 & 1184 & 37 & 19.3 \\
9 & 23 & 1278 & 31 & 19.5 \\
10 & 23 & 973 & 58 & 17.1 \\
10 & 26 & 1039 & 72 & 18.4 \\
10 & 29 & 1226 & 60 & 22.5 \\
10 & 32 & 1373 & 50 & 26.5 \\
10 & 35 & 1864 & 56 & 28.5 \\
10 & 32 & 2140 & 56 & 24.4 \\
10 & 29 & 2310 & 57 & 20.7 \\
\hline
\end{tabular}

\begin{tabular}{|c|c|c|c|c|c|c|c|}
\hline \multirow{2}{*}{$\begin{array}{l}\text { Tubular } \\
\text { specimen }\end{array}$} & \multirow{2}{*}{$\begin{array}{l}\Delta K_{\mathrm{II}}^{\text {nom }} \\
(\mathrm{MPa} \sqrt{\mathrm{m}})\end{array}$} & \multirow{2}{*}{$\begin{array}{l}\sigma_{\mathrm{N}} \\
(\mathrm{MPa})\end{array}$} & \multirow{2}{*}{$\begin{array}{l}2 a \\
(\mu \mathrm{m})\end{array}$} & \multicolumn{2}{|c|}{$c_{0}(\mathrm{MPa})$} & \multicolumn{2}{|c|}{$\Delta K_{\mathrm{II}}^{\mathrm{eff}}$} \\
\hline & & & & left & right & left & right \\
\hline 1 & 33.3 & 0 & 4153 & 26 & 38 & 28.0 & 26.1 \\
\hline 1 & 38.7 & 0 & 5372 & 0 & 2 & 38.6 & 38.2 \\
\hline 1 & 53.7 & 0 & 8012 & 0 & 0 & 53.7 & 53.7 \\
\hline 1 & 69 & 0 & 10372 & 0 & 0 & 69.0 & 69.0 \\
\hline 2 & 43.4 & -150 & 4035 & 96 & 94 & 26.5 & 26.3 \\
\hline 2 & 49.3 & -150 & 5207 & 65 & 60 & 37.5 & 38.0 \\
\hline 2 & 61.7 & -150 & 6295 & 110 & 86 & 39.1 & 43.7 \\
\hline
\end{tabular}

(b)
Table 2 Values of the friction stress and effective stress intensity factor determined for (a) CTS and (b) tubular specimens 
have been observed to propagate in shear for much smaller stress intensity factors. (Due to the unknown three-dimensional aspect of naturally initiated cracks in tubular specimens, the evaluation of $K_{\mathrm{II}}$ cannot be very accurate. But using the expression of $K_{\mathrm{II}}$ given by Kassir and $\operatorname{Sih}^{15}$ for an elliptical crack in an infinite plate in shear, and thus neglecting the correction for finite thickness of the tube wall and the gradient of the shear stress, which can be advocated due to the shallowness of natural cracks in torsion, we find that for a $300 \mu \mathrm{m}$-long crack, and a stress range of $\pm 550 \mathrm{MPa}$, the value of $\Delta K_{\mathrm{II}}$ is about $6 \mathrm{MPa} \sqrt{\mathrm{m}}$, assuming an aspect ratio of 0.2 .)

A tentative explanation will be proposed, based on the idea put forward by Hourlier et al., ${ }^{16}$ that the crack path, in multiaxial loading, is determined by a maximum velocity criterion. The contradiction mentioned above could be solved if, in this maraging steel—and perhaps in some other materials depending on their mode I/ mode II crack growth kinetics-there existed two distinct domains (domain 2 and 4 in Fig. 12), bounded in $\Delta K_{I I}^{\text {eff }}$ values, in which mode II is faster, separated by a domain where mode I prevails (domain 3). Note that the growth rates for the two modes must not be compared for equal $\Delta K_{\mathrm{I}}^{\text {eff }}$ and $\Delta K_{\mathrm{II}}^{\text {eff }}$. Rather, the growth rate corresponding to the mode I stress intensity factor for an incipient branch crack at the tip of a mode II crack should be compared to the growth rate of the main crack, and vice versa.

Figure 12 is reminiscent of fig. 9(a) in Ref. 17, where Brown et al. plot the growth rates as a function of crack depth for the three stages in the crack development likely to be observed in torsional fatigue, at a given stress range (stage I and III correspond to shear modes, and stage II to the opening mode) and where the opening

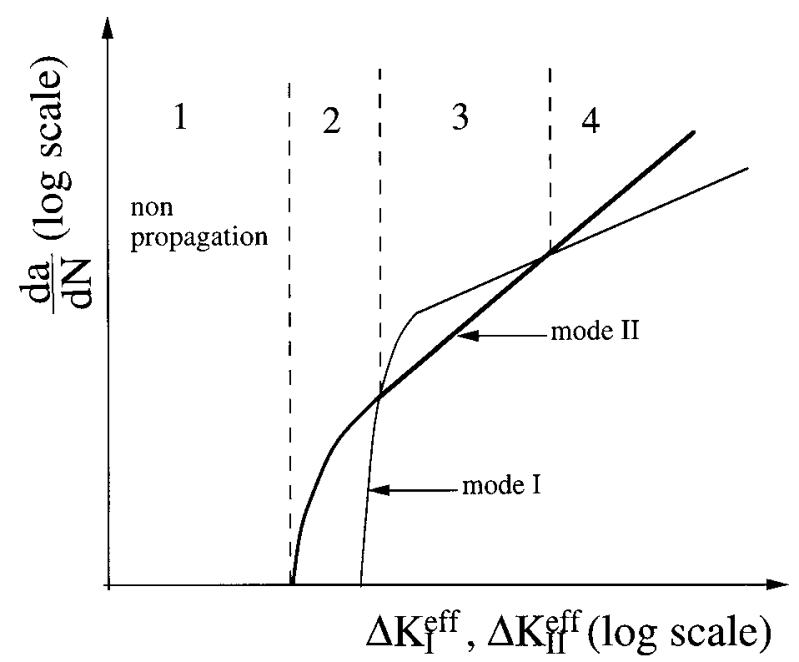

Fig. 12 Hypothetical layout of mode I and II crack growth curves in the maraging steel and schematic delimitation of four domains with respect to the behaviour of cracks. mode is the fastest only for intermediate crack depth, and thus intermediate $K$-values.

In the lower part of domain 2, branching would not occur simply because the stress intensity factor of the branch would be less than the threshold value for mode I propagation, while in the upper part of domain 2, the development of a branch could be possible, although slower than the mode II propagation of the main crack. The materials for which mode II was reported to occur below a given threshold in $\Delta K_{\text {II }}$ probably have such a domain, and crack arrest, as in Ref. 3 is observed whenever $\Delta K_{\mathrm{II}}^{\text {eff }}$, initially in domain 2 , decreases down to the limit of domain 1. For the 7075-T6 aluminium alloy tested by Otsuka et al., ${ }^{2}$ in which mode II propagation is reported to occur above a given $\Delta K_{\mathrm{II}}$, the mode $\mathrm{I}$ and mode II crack growth curves might be positioned similar to the maraging steel, thus defining four domains, but domain 2 might be very narrow and have been passed unnoticed (the crack monitoring system used in Ref. 2 is not specified). Note that the zig-zag path of nominally mode I cracks often observed at low $\Delta K_{\mathrm{I}}$ values [see, e.g. Figure $5(\mathrm{a})]$ shows that shear mode propagation is preferred at the local scale in this regime. This also supports the existence of domain 2.

The value of $17 \mathrm{MPa} \sqrt{\mathrm{m}}$ determined in the case of a maraging steel represents the limit between domains 4 and 3 .

The unusual crack path observed in reversed torsion for a stress range of $400 \mathrm{MPa}$ is in fact perfectly consistent with the scheme of Fig. 12. After crack initiation and stage I growth (domain 2), the limit of domain 3 was reached and branching occurred. Then, as a result of the accelerating mode I propagation, the limit of domain 4 was subsequently reached, whence the return to the shear mode. This point of view is supported by the value of the mode I crack growth rate just before branching: $0.1 \mu \mathrm{m} /$ cycle, which corresponds to the minimal mode II crack growth rate measured on precracked CTS specimens (see Fig. 11).

The crack paths in reversed torsion for stress ranges higher than $550 \mathrm{MPa}$ are more difficult to explain on the basis of Fig. 12. The fact that cracks develop entirely in shear mode, from initiation to failure, for amplitudes above $550 \mathrm{MPa}$, in plain tubular specimens, suggests that the shear mode is always the fastest in these conditions. [In the same way, in fig. 9(b) of Ref. 17 which was plotted for high-amplitude torsional loading, shear mode crack growth is faster than mode I-stage II crack growth, in the whole range of crack depth.] In fact, it was shown that mode I crack growth is not uniquely correlated with the stress intensity factor, but can be affected by the $T$ stress (a non-singular stress parallel to the $\mathrm{crack}^{18}$ ), provided that the applied stress level is a substantial fraction of the yield stress (more than 50\% according to 
Miller and Brown ${ }^{19}$ ). In torsion, the second principal stress generates a cyclic $T$ stress, $180^{\circ}$ out-of-phase with the opening stress. Then, $T$ stress effects on mode I crack growth can be expected in this maraging steel, for shear stresses higher than $500 \mathrm{MPa}$. But the sense of this effect (that is acceleration or retardation) is not known ( $T$ stress effects seem to depend on the material properties, ${ }^{20}$ and data on cyclically softening materials are missing, to the authors knowledge). A careful examination of the mode I crack growth kinetics measured in tubular specimens of mild steel during reversed torsion tests performed at various stress ranges by Pook and Denton, ${ }^{21}$ suggests a deceleration, at a given $\Delta K_{\mathrm{I}}$, when the stress range-and thus the $T$ stress range-increases. If the tendency was similar in the maraging steel, the curve corresponding to mode I growth in Fig. 12 would be shifted to the right at high stress ranges, so that it would never cross the mode II curve. This would make the maximum velocity criterion coherent with the observed crack paths.

An attempt was made to prove the retardation effect associated with the cyclic $T$ stress: a pierced tubular specimen was loaded in low-amplitude repeated torsion so as to produce $1 \mathrm{~mm}$-long precracks at $45^{\circ}$ to the axis on each side of the hole. It was then loaded in reversed torsion at $\pm 525 \mathrm{MPa}$ so as to measure the mode I crack growth kinetics at this stress range. However, the cracks branched at once and propagated in shear mode. Mode I propagation seems thus impossible in precracked tubular specimens submitted to reversed torsion above $52 \%$ of the yield stress.

\section{CONCLUSIONS}

Torsional fatigue cracks propagate in shear mode, in plain tubular specimens of M250 maraging steel, for stress ranges from $90 \%$ to $40 \%$ of the yield stress. This cannot be explained in terms of microcrack coalescence for the smallest stress range, for which microcracks are scarce. Furthermore, mode I propagation is unstable in precracked tubular specimens submitted to reversed torsion, for stress ranges higher than $\pm 525 \mathrm{MPa}$.

Mode II crack growth was observed to occur for substantial distances (up to $5 \mathrm{~mm}$ ) in precracked CTS specimens under small-scale yielding conditions. Lowfrequency testing accelerates mode II propagation and makes it more stable. Friction stresses along the crack flanks shield the applied load and are responsible for a very progressive deceleration leading to crack branching when the effective stress intensity factor (deduced by an inverse method from the measured displacement profiles) decreases down to $17 \mathrm{MPa} \sqrt{\mathrm{m}}$. The measured crack growth rates, in pure mode II as well as with a superimposed compressive stress, correlate much better with the calculated effective stress intensity factors than with the nominal $\Delta K_{\text {II }}$ values.

A tentative explanation of the crack paths observed in this material in plain tubular specimens in torsional fatigue is proposed based on a maximum velocity criterion. It is suggested that for low-stress ranges, for which mode I kinetics are uniquely determined by $\Delta K_{\mathrm{II}}^{\text {eff }}$, it crosses the mode II kinetics twice, defining two distinct ranges of $\Delta K_{\mathrm{II}}^{\text {eff }}$, in which mode II is faster than mode I. For higher amplitudes, however, the mode I kinetics would be $T$ stress dependent, and, in the case of reversed torsion, slower than the mode II kinetics in the whole range of $\Delta K$ values, this explains why cracks develop in shear mode from initiation to failure, under these conditions.

\section{Acknowledgement}

The financial support of this study was provided by SNECMA and CNRS.

\section{REFERENCES}

1 D. F. Socie (1987) Fatigue damage maps. In: Fatigue 87, 3rd Int. Conference on Fatigue and Fatigue Threshold, University of Virginia (Edited by Ritchie and Starke), EMAS, Wareley, Vol. 2, pp. 599-616.

2 A. Otsuka, K. Mori and K. Togho (1987) Mode II fatigue crack growth in aluminium alloys. In: Current Research on Fatigue Cracks, Current Japanese Materials Research, Elsevier, London, Vol. 1, pp. 149-180.

3 G. Hua, N. Alagok, M. W. Brown and K. J. Miller (1985) Growth of fatigue cracks under combined mode I and mode II loads. In: Multiaxial Fatigue, ASTM-STP 853, pp. 184-202.

4 E. K. Tschegg and S. E. Stanzl (1988) The significance of sliding mode crack closure on mode III fatigue crack growth. In: Basic Questions in Fatigue, I (Edited by J. T. Fong and R. J. Fields), ASTM STP 924, Philadelphia, pp. 214-232.

5 M. C. Smith and R. A. Smith (1988) Toward an understanding of mode II fatigue crack growth. In: Basic Questions in Fatigue, I (Edited by J. T. Fong and R. J. Fields), ASTM STP 924, Philadelphia, pp. 260-280.

6 Y. Murakami (1987) Stress Intensity Factors Handbook, Vol. 2. Pergamon Press.

7 D. François, A. Pineau and A. Zaoui (1993) Comportement Mécanique des Matériaux, Hermès.

8 V. Doquet, D. Caldemaison and T. Bretheau (1994) Combined tension and torsion cyclic tests inside a scanning electron microscope. In: Proceedings of the Fourth International Conference on Biaxial and Multiaxial Fatigue, St Germain en Laye, Vol. II, pp. 19-26.

9 F. Bowden and D. Tabor (1959) Friction et Lubrification, Dunod, Paris.

10 G. Clark (1986) Fatigue at low growth rates in a maraging steel. Fatigue Fract. Engng Mater: Struct. 9(2), 131-142.

11 C. H. Wang and K. J. Miller (1991) The effect of mean shear stress on torsional fatigue behaviour. Fatigue Fract. Engng Mater Struct. 14, 293-307. 
12 V. Doquet (1997) Crack initiation mechanisms in torsional fatigue. Fatigue Fract. Engng Mater. Struct. 20, 227-235.

13 V. Doquet (in press) Micromechanical simulations of Stage I fatigue crack growth under multiaxial loading. In: Small Fatigue Cracks: Mechanics and Mechanisms (Edited by K. S. Ravichandran, R. O. Ritchie and Y. Murakami), Elsevier Science.

14 C. Pinna and V. Doquet (1997) Quantification of friction effects during mode II fatigue crack propagation in a maraging steel. In: Proceedings 5th Int. Conference Biaxial/Multiaxial Fatigue and Fracture (Edited by E. Macha and Z. Mròz), Cracow, Poland, Vol. 2, pp. 97-113.

15 M. K. Kassir and G. C. Sih (1966) Three dimensional stress distribution around an elliptical crack under arbitrary loadings. 7. Appl. Mech. 33, 601-611.

16 F. Hourlier, H. d'Hondt, M. Truchon and A. Pineau (1982) Fatigue crack path behavior under polymodal fatigue. In: Multiaxial Fatigue (Edited by K. J. Miller and M. W. Brown), ASTM STP 853, ASTM, Philadelphia, pp. 228-248.
17 M. W. Brown, K. J. Miller, U. S. Fernando, J. R. Yates and D. K. Suker (1994) Aspects of multiaxial fatigue crack propagation. In: Proc. 4th Int. Conference Biaxial/Multiaxial Fatigue, Saint Germain en Laye, Vol. 1, pp. 3-16.

18 M. B. Williams (1957) On the stress distribution at the base of a stationary crack. F. Appl. Mech. 24, 109-114.

19 K. J. Miller and M. W. Brown (1985) Mode I fatigue crack growth under biaxial stress at room and elevated temperature. In: Multiaxial Fatigue, ASTM STP 853, Philadelphia, pp. $135-152$.

20 H. Kitagawa, R. Yuuki, K. Togho and M. Tanabe (1985) $\Delta K-$ dependency of fatigue crack growth of single and mixed mode cracks under biaxial stress. In: Multiaxial Fatigue, ASTM STP 853, Philadelphia, pp. 164-183.

21 L. P. Pook and K. Denton (1972) Fatigue crack growth in thin walled mild steel cylinders loaded in torsion. Int. 7. Fracture Mech. 8, 118-120. 